\title{
Act versus Impact: Conservatives and Liberals Exhibit Different Structural Emphases in Moral Judgment
}

\author{
Ivar R. Hannikainen, Ryan M. Miller, \& Fiery A. Cushman
}

\begin{abstract}
Conservatives and liberals disagree sharply on matters of morality and public policy. We propose a novel account of the psychological basis of these differences. Specifically, we find that conservatives tend to emphasize the intrinsic value of actions during moral judgment, in part by mentally simulating themselves performing those actions, while liberals instead emphasize the value of the expected outcomes of the action. We then demonstrate that a structural emphasis on actions is linked to the condemnation of victimless crimes, a distinctive feature of conservative morality. Next, we find that the conservative and liberal structural approaches to moral judgment are associated with their corresponding patterns of reliance on distinct moral foundations. In addition, the structural approach uniquely predicts that conservatives will be more opposed to harm in circumstances like the wellknown trolley problem, a result which we replicate. Finally, we show that the structural approaches of conservatives and liberals are partly linked to underlying cognitive styles (intuitive versus deliberative). Collectively, these findings forge a link between two important yet previously independent lines of research in political psychology: cognitive style and moral foundations theory.
\end{abstract}

Political conservatives and liberals disagree on a number of moral issues. ${ }^{1}$ This is evident in matters of public policy, and also confirmed in laboratory investigations (Inbar, Pizarro, \& Bloom, 2009; Piazza \& Sousa, 2014). A core ambition of empirical research in political psychology is to understand these differences in terms of underlying psychological traits (see Hannikainen, Cabral, Machery, \& Struchiner, 2016). One successful approach, moral foundations theory, highlights differences in the content of liberal and conservative moral concerns (Graham, Haidt, \& Nosek, 2009; Haidt \& Graham, 2007). In particular, liberals place slightly greater importance on the values of care and fairness, while conservatives place substantially greater value on the virtues of loyalty toward one's ingroup, respect for authority, and upholding sanctity and bodily purity.

Meanwhile, a growing body of research demonstrates the importance of different structural emphases in moral judgment: specifically, the distinction between an emphasis on the action a person performs (e.g., 'punching'), versus an emphasis on the expected outcomes of that person's behavior (e.g., 'causing a bruise'). This

\footnotetext{
${ }^{1}$ Since our samples are overwhelmingly US-based, we use the term 'liberal' in our studies and in writing to refer to participants left of center, whether on social or fiscal matters. Readers unfamiliar with United States politics should note that this use of the term 'liberal' is synonymous with 'progressive'.
}

structural distinction appears in numerous contemporary theories of moral psychology. The literature on 'protected values' emphasizes that people often find certain behaviors categorically impermissible even when the outcomes of those behaviors are positive (e.g., genetically engineering more intelligent humans), but evaluate other behaviors according simply to their outcomes (Baron \& Spranca, 1997; Bartels, 2008). The literature on welfare dilemmas, such as the trolley problem, also depends fundamentally on a distinction between an affective response to an action and a putatively 'cognitive' form of outcome maximization (Cushman, Young, \& Hauser, 2006; Greene, Nystrom, Engell, Darley, \& Cohen, 2004; Greene, Sommerville, Nystrom, Darley, \& Cohen, 2001; Petrinovich, O'Neill, \& Jorgensen, 1993). And, there is now a large literature showing that people sometimes condemn actions even when they cause no harm, such as kissing a sibling or eating one's dead pet (Haidt, Koller, \& Dias, 1993; Horberg, Oveis, Keltner, \& Cohen, 2009). Taken together, these theories demonstrate the scientific value of distinguishing between psychological processes that categorically prohibit actions and those that instead value actions contingent upon their expected outcomes.

These theories resonate with a growing body of research outside the moral domain indicating that decision-making and behavior are guided by two distinct processes of valuation (Daw \& Shohamy, 2008; Dayan \& Niv, 2008; Gershman, Markman, \& Otto, 2014; Gläscher, Daw, Dayan, 
\& O'Doherty, 2010; Otto, Gershman, Markman, \& Daw, 2013). One (model-free) process selects behaviors based on their intrinsic value representations, while another (model-based) process selects behaviors contingent on the rewards and punishments that result from them. It has been suggested that this framework may help to explain many of the findings in moral psychology described above (Crockett, 2013; Cushman, 2013; Miller \& Cushman, 2013).

However, to our knowledge, no past work has explicitly applied the action/outcome distinction to the study of political psychology. Our approach complements past research on moral foundations, but it is also quite distinct: Whereas moral foundations theory focuses on the content of moral codes, our aim is to examine different structural emphases. It is indisputable that liberals and conservatives moralize different types of conduct; our present objective is to understand whether these disagreements are linked to differences in the psychological representation of moral value during learning and decision-making.

Is there reason to suspect that political orientations can be tied to different structural approaches in moral judgment? Three existing lines of evidence support the hypothesis that conservatives are relatively more sensitive to action-based values while liberals are relatively more sensitive to outcome-based values. First, the deontological response to personal moral dilemmas has been shown to depend on an aversion to harmful action (Miller, Hannikainen, \& Cushman, 2014; Patil, 2015). In addition, recent reports indicate that conservatives tend to make deontological judgments about these cases more frequently than do liberals (Graham, Iyer, Sherman, Hawkins, \& Nosek, 2017; Piazza \& Sousa, 2014). From a content-based perspective, it is not clear why this would be: Both the utilitarian action of sacrificing one life to save many and its deontological prohibition fall clearly within the domain of harm concerns. From a structural perspective, however, they differ in that one arises from the valuation of outcomes-the utilitarian response-while the other is motivated by an aversion to action - the deontological response.

Second, a structural approach might help to explain conservatives' and liberals' contrasting attitudes to harmless taboos, such as kissing a sibling, peeing in public or eating one's dead pet (Inbar et al., 2009). Since these behaviors do not cause harm, there is a clear a priori prediction that permissive attitudes involve a focus on the behavior's expected outcomes, while attitudes of moral opposition might depend on representations of the action in isolation.

Third, the structural hypothesis dovetails with evidence that increased religiosity leads to a preference for rule-based over outcome-based moral judgment (Piazza, 2012). Given the strong association between religiosity and social conservatism (Olson \& Green, 2006), and the conceptual connection between moral rules and categorical prohibitions on action (Cushman, 2013), this prior result may in part reflect a conservative structural emphasis on actions.

These past lines of research build the case for a parsimonious explanation: Stereotypically liberal and conservative moral judgments-concerning the scope of permissible harm, for instance, or the moral status of purity violations - may reflect the interplay of distinct structural emphases, on the intrinsic moral status of actions (greater among conservatives) versus the aggregate value of expected outcomes (greater among liberals). This structural perspective may shed light on public policy disputes as well: Debates about abortion and euthanasia, in which liberals tend to favor more permissive policies while conservatives favor more restrictive policies, feature at their root the tension between a categorical prohibition of some action-type, versus a case-by-case weighing of costs and benefits (in some sense analogous to the trolley problem). Similarly, political divisions with regard to LGBT rights, for instance, likely depend in part on underlying moral appraisals, with a structural emphasis on actions eliciting stronger condemnation and an emphasis on outcomes finding no basis for opposition. Therefore, the present study aims to illustrate the value of characterizing moral disagreements between conservatives and liberals in terms of a structural division between action-based and outcome-based value representations.

\section{Study 1}

In Study 1 we examine participants' structural approaches to moral judgment, asking whether they place greater emphasis on the feelings associated intrinsically with actions or instead on the outcomes that those actions are likely to cause. Our prediction is that conservatives will emphasize the former, while liberals will emphasize the latter.

Our experimental approach is motivated by a particular model of the origin of action-based moral values, according to which action-based moral values (e.g., judging that sexual intercourse with a sibling is wrong) are grounded in corresponding aversions to performing those actions oneself (e.g., having a strong aversion to 
sexual intercourse with one's own sibling). In other words, we evaluate whether an action is right or wrong for somebody else by considering our feelings about performing the action ourselves, a process which we have termed "evaluative simulation" (Hannikainen, 2014; Miller \& Cushman, 2013). Consistent with this proposal, past research finds that the condemnation of third-party behavior is driven by individual differences in the aversion to the equivalent firstperson action (Lieberman \& Lobel, 2012; Miller et al., 2014; Patil, 2015). We predict that conservative participants will report greater reliance on this approach to moral judgment than will liberal participants.

To test these related predictions, we designed two empirical measures for Study 1. The first of these evaluated participants' structural emphasis on actions versus outcomes across a series of 18 items. The second evaluated participants' use of evaluative simulation specifically. As discussed above, with a structural emphasis on actions, the division between first- and third-person evaluations plays a central role: one's own felt aversion to performing an action may become the basis for third-party evaluation. In contrast, on an outcome assessment, this division need not play any substantial role: whether from a first- or thirdperson perspective, actions are judged by considering whether they harm or help those affected

\subsection{Method}

612 participants (306 women) logged on to the Moral Sense Test, a website hosted by the Psychology Department at Harvard University, which has been used in previous studies of moral psychology (Cushman et al., 2006; Cushman, Knobe, \& Sinnott-Armstrong, 2008). Participants first read a brief introduction to the study and provided their written consent. Next, participants completed our measures of structural emphasis (see below) and voluntarily provided demographic information, including their age, gender*, educational attainment, religiosity*, and their political views on social* ('When it comes to social issues, how liberal or conservative are you?') and fiscal* (When it comes to economic issues, how liberal or conservative are you?') issues. An asterisk $\left(^{*}\right)$ indicates optional fields.

\subsubsection{Structural emphases}

We developed an 18-item measure to assess differences in structural emphasis during moral judgment. Nine action focus items highlight the relevance of one's own feelings about candidate actions when making moral judgments (e.g., 'By and large, morality is about doing what feels right', 'If a behavior is morally right, it shouldn't make me feel uncomfortable'). The other nine outcome focus items emphasize the expected outcomes of candidate actions (e.g., 'In order to be moral you have to pay close attention to the impact of your decisions', 'Morality is about helping others and not harming them'). The items were presented in an order randomized for each participant and mixed across subscales, in order to preclude the impact of systematic order effects upon our analyses. Mean agreement yielded an action focus (AF) and outcome focus (OF) score for each participant.

After the action and outcome foci items, we assessed the degree to which participants engage in evaluative simulation (ES) versus an assessment of outcomes (OA) in making third-party moral judgments, through a variety of measures linked to two paragraphs:

Act: I know what is right and wrong by listening to my own conscience. So, when judging another person's behavior, I put myself in their shoes and ask myself what I would have done. If I would have done the same, then what they did is morally right. But if I could not have done the same according to my conscience, then the behavior was morally wrong for someone else to do.

Impact: I judge moral decisions by putting myself in the shoes of the people who are affected by those decisions. If performing an action hurts others, then I consider it morally wrong. If performing an action benefits others, I consider it morally acceptable. The primary purpose of morality is to help other people and not hurt them. Therefore, making a moral judgment is all about adopting the perspective of anybody who will be affected.

First participants indicated a dichotomous preference for one or the other approach, i.e., their endorsement of evaluative simulation (Act) vs. outcome assessment (Impact). Participants then estimated the influence of each approach (and of any other approach they employ) during thirdparty moral evaluation, on three independent scales from 1: 'not at all' to 7: 'extremely', yielding the absolute ratings of evaluative simulation, outcome assessment, and other approaches. Finally, they indicated the relative influence of the Act and Impact approaches on an eleven-point 
bipolar scale from 1: ' $100 \%$ Act, $0 \%$ Impact' to 11: ' $0 \%$ Act, $100 \%$ Impact', yielding the relative rating of evaluative simulation vs. outcome assessment.

We predicted a relationship between structural emphases on actions versus outcomes (indexed by action focus and outcome focus scores) and approaches to third-party judgment. That is, evaluative simulation should depend on a structural emphasis on actions, just as outcome assessment should depend on a structural emphasis on outcomes.

\subsection{Results}

Action focus and outcome focus were positively correlated, $r(612)=.47, p<.001$. An item analysis on action and outcome foci revealed satisfactory reliability for both sets of items, AF $a$ $=.73$, OF $a=.75$. Every action item increased the reliability of the action focus subscale, and all but one outcome item ('If an action truly hurts nobody, then it probably isn't wrong.') increased the reliability of the outcome focus subscale.

Table 1. Rotated Factor Analysis: Factor Loadings and Uniqueness V alues

\begin{tabular}{|c|c|c|c|c|}
\hline & Item & F1 & F2 & $\begin{array}{l}\text { Uni } \\
q .\end{array}$ \\
\hline A1 & By and large morality is about doing what feels right. & & .47 & .75 \\
\hline A2 & When faced with a moral dilemma I usually listen to my own conscience. & & .34 & .87 \\
\hline A3 & $\begin{array}{l}\text { In a way, morality is like art. When you see something, you know how you } \\
\text { feel about it. }\end{array}$ & & .40 & .80 \\
\hline A4 & $\begin{array}{l}\text { Dignity is a big part of my morality, so there are certain things I could never } \\
\text { do. }\end{array}$ & & .45 & .78 \\
\hline A5 & $\begin{array}{l}\text { If only people listened to their inner voice, they would make better moral } \\
\text { choices. }\end{array}$ & & .42 & .72 \\
\hline A6 & $\begin{array}{l}\text { At the end of the day, good moral decisions are those decisions you can live } \\
\text { with. }\end{array}$ & & .54 & .68 \\
\hline A7 & $\begin{array}{l}\text { Something that feels repugnant for me to do is probably wrong for someone } \\
\text { else to do. }\end{array}$ & & .40 & .82 \\
\hline A8 & Certain ways of behaving are wrong no matter what the situation. & & .45 & .78 \\
\hline A9 & If a behavior is morally right, it shouldn't make me feel uncomfortable. & & .38 & .82 \\
\hline O1 & $\begin{array}{l}\text { I'm more than willing to make sacrifices for the better of others and the } \\
\text { future. }\end{array}$ & .40 & & .77 \\
\hline $\mathrm{O} 2$ & Morality is about helping others and not harming them. & .64 & & .57 \\
\hline $\mathrm{O} 3$ & As far as morality goes, my goal is to care about people equally. & .50 & & .72 \\
\hline $\mathrm{O} 4$ & The point of morality is to end suffering and promote happiness. & .56 & & .68 \\
\hline O5 & If an action truly hurts nobody, then it probably isn't wrong. & & & .91 \\
\hline O6 & $\begin{array}{l}\text { If only people cared more about each other, they would make better moral } \\
\text { decisions. }\end{array}$ & .51 & & .68 \\
\hline $\mathrm{O} 7$ & $\begin{array}{l}\text { In order to live morally in your day-to-day, you have to constantly step out } \\
\text { of your shoes. }\end{array}$ & .48 & & .77 \\
\hline O8 & $\begin{array}{l}\text { In order to be moral you have to pay close attention to the impact of your } \\
\text { decisions. }\end{array}$ & .51 & & .73 \\
\hline O9 & $\begin{array}{l}\text { Considering the feelings of others is an important part of deciding what's } \\
\text { right. }\end{array}$ & .49 & & .73 \\
\hline
\end{tabular}

Notes. F1: Factor 1 loadings; F2: Factor 2 loadings; Uniq.: uniqueness. Blanks represent factor loadings < .3. 
We performed an exploratory factor analysis of the correlation matrix including all eighteen action and outcome foci items, using the principal-factor method. This analysis initially retained seven factors with positive eigenvalues. Only two factors presented eigenvalues $>1$, and a Cattell scree test also supported a two factor solution. The factor loadings and uniqueness values for all eighteen items, after an orthogonal varimax rotation, are displayed in Table 1 below. Every item loaded $>$ .3 on its corresponding factor and $\leq .3$ on the other factor, with the exception of an outcome focus item (O5) which loaded on neither factor. This result largely confirms the scale's composition of two factors corresponding to our predictions.

We found also that approaches to third-party moral judgment were linked with structural emphases in the predicted manner: Greater action focus was associated with higher ratings of evaluative simulation, $r(612)=.24, p<.001$; just as greater outcome focus was associated with higher ratings of outcome assessment, $r(612)=$ $.46, p<.001$.

\subsubsection{Structural emphases and political orientation}

As predicted, social conservatives demonstrated greater action focus, $r(607)=.18, p$ $<.001$, and lesser outcome focus, $r(607)=-.15, p$ $<.001$, than did social liberals. Fiscal political orientation correlated with action focus, $r(610)=$ $.09, p=.02$, as did religiosity, $r(611)=.18, p<$ .001 , but neither correlated with outcome focus. In a multiple regression model predicting social political orientation $\left(\mathrm{F}(2,607)=33.4, p<.001, r^{2}\right.$ $=.10)$, action focus and outcome focus demonstrated independent effects, $\mathrm{AF} \beta=0.32, t$ $=7.18, p<.001$, OF $\beta=-0.29, t=-6.77, p<.001$.

With our measures of third-party evaluation, we obtained the corresponding pattern of results: Participants who endorsed evaluative simulation $(\mathrm{n}=234, \mathrm{M}=3.53, \mathrm{SD}=1.64)$ were more socially conservative than participants who endorsed outcome assessment $(\mathrm{n}=373, \mathrm{M}=$ $2.99, \mathrm{SD}=1.66), t(605)=3.91, p<.001, d=0.33$. Furthermore, ratings of evaluative simulation were associated with a conservative stance on social issues, $r(607)=.14, p<.001$, while outcome assessment was associated with liberal views on social issues, $n(607)=-.18, p<.001$, and these were independent effects in a multiple regression model $\left(\mathrm{F}(2,604)=14.6, p<.001, r^{2}=.04\right), \mathrm{ES}: \beta$ $=0.12, t=2.96, p=.003$; OA: $\beta=-0.16 ; t=$ $4.10, p<.001$.

\subsection{Discussion}

Social conservatives placed a greater structural emphasis on actions and tended to endorse evaluative simulation, while social liberals placed a greater structural emphasis on outcomes and tended to favor outcome assessment (over evaluative simulation). Political orientation on fiscal issues did not yield equivalently systematic effects on structural emphasis and, surprisingly, neither did religiosity (but see Piazza, 2012). Overall this provides evidence in favor of the hypothesis that political orientation is associated with different structural emphases in moral judgment. We should note, however, that the effect sizes were small to moderate throughout.

\section{Study 2}

Study 1 found evidence that social conservatives are more likely to endorse an actionbased approach to moral judgment. Some of this evidence comes from their endorsement of evaluative simulation, an approach to moral evaluation grounded in imagining how one would feel performing a putative moral violation oneself. However, our methods in Study 1 were novel. Thus, in Study 2 we sought to validate these measures by relating them to the moral judgment of 'victimless crimes' (Haidt et al., 1993). This category is composed of putative moral violations - such as consensually kissing a sibling, peeing in public, or eating one's dead pet-that result in no appreciable harm but violate prevailing standards of purity, sanctity and/or decency. In addition, it is known that conservatives tend to condemn these behaviors more harshly than do liberals (Inbar et al., 2009).

Therefore, victimless crimes provide a critical test of our model of structural emphasis. Clearly, from an outcome-focused perspective these actions should be considered morally acceptable. By definition, they have no harmful outcome. Meanwhile, the moral condemnation of victimless offenses might depend on action-based value representations, elicited through evaluative simulation (Cushman, 2013; Miller \& Cushman, 2013). For instance, because people are personally disgusted at the thought of eating their own dead pet, they conclude that it is morally wrong for others to do so.

Past studies have shown an association between the moral condemnation of victimless violations of purity norms and individual differences in sensitivity to disgust (Horberg et al., 2009; Inbar et al., 2009). According to the structural hypothesis, this linkage between personal aversions and moral judgments of third- 
party behavior may result from the exercise of evaluative simulation: i.e., the disgust response stems from a simulation of the target action, which then undergirds the attitude of moral condemnation.

To test this, we included a popular measure of sensitivity to disgust. We predicted that the established correlation between disgust sensitivity and condemnation of purity domain issues would be moderated by our measures of evaluative simulation. That is, disgust sensitivity should predict moral judgment significantly better among participants who report using their own personal aversion to performing actions as a basis for making moral judgments of others.

\subsection{Methods}

407 participants (194 women) voluntarily logged on to the Moral Sense Test, read a brief introduction to the study and provided their written consent. Participants completed the assessment of structural emphasis and a block of eight scenarios describing violations of the purity domain, in a counterbalanced order across participants.

The eight scenarios were presented in a pseudorandom order and described a third-party agent performing actions that may evoke core disgust (e.g., smearing feces on oneself), sexual disgust (e.g., French-kissing one's uncle at a family party), or animal-reminder disgust (e.g., getting plastic surgery that adds a two-inch tail to the end of one's spine). Participants rated the moral wrongness of these actions on a seven-point scale from 1: 'Not morally wrong at all' to 7: 'Very morally wrong'.

At the end, participants completed the Disgust Scale-Revised (DS-R; Haidt, McCauley \& Rozin, 1994, modified by Olatunji et al. 2007), a widely used instrument for assessing individual differences in sensitivity to disgust that correlates with behavioral responses to real-life disgust elicitors (Rozin, Haidt, McCauley, Dunlop, \& Ashmore, 1999) and optionally provided demographic information.

\subsection{Results}

Judgments of the eight purity violations were averaged to form a single index of moral judgment per participant $(a=.88)$. We replicated the relationship between political orientation and moral judgment of purity violations, $r(396)=.38$, $p<.001$, indicating that conservative participants tended to condemn purity violations more strongly than did liberal participants.

As predicted, action focus correlated with moral judgment, $r(407)=.30, p<.001$. Specifically, the more participants tended to emphasize the intrinsic value of actions the more they condemned third-party violations of the purity domain. By contrast, no relationship was found between moral judgment and a focus on outcomes, $p>.7$ (see Fig. 1). In a multiple regression $\left(\mathrm{F}(3,392)=29.0, \mathrm{p}<.001, r^{2}=.18\right)$, the effect of action focus remained significant after controlling for outcome focus and political orientation; $\mathrm{AF} \beta=0.23, t=4.62, p<.001$, OF $\beta$ $=-0.05, t=-1.03, p=.30$, politics $\beta=0.32, t=$ $6.63, p<.001$.

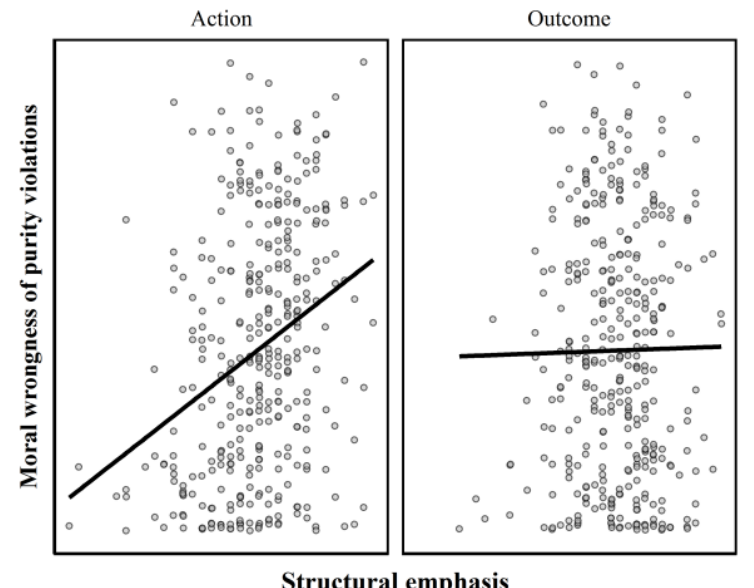

Figure 1. Moral wrongness of purity violations by structural emphases.

We also found the predicted relationship between evaluative simulation and the condemnation of victimless crimes. Participants who employed evaluative simulation judged the victimless crimes more severely ( $\mathrm{n}=173, M=$ 3.56, $S D=1.68$ ) than did participants who reported performing an assessment of outcomes $(\mathrm{n}=234, M=3.14, S D=1.55), t(405)=2.66, p=$ $.008, d=0.27$. Similarly we observed a positive correlation between absolute ratings of evaluative simulation and moral judgment, $r(407)=.17, p<$ .001 , although this correlation depended entirely on the order of presentation. ${ }^{2}$ Ratings of outcome assessment did not correlate with moral judgment, $p>.6$.

\subsubsection{Disgust sensitivity}

Replicating previous studies, we found that participants' disgust sensitivity correlated with their moral judgments, $r(384)=.41, p<.001$. We

\footnotetext{
${ }^{2}$ Evaluative simulation correlated with moral condemnation only when structural emphasis was assessed after the block of purity violations: SE-After $r(201)=.32, p<.001 ;$ SE-Before $r(206)=.01, p>.8$.
} 
hypothesized that this relationship was driven by participants who employed evaluative simulation. That is, the disgust response should serve as a basis for the condemnation of third-party behavior to the extent that participants take their own aversions to performing disgust-eliciting behavior as relevant to judging others, instead of assessing the behavior's likely outcomes. In order to test this hypothesis, we examined the pairwise correlations between moral judgment and disgust sensitivity, comparing participants who reported employing evaluative simulation to those who reported performing an assessment of outcomes. A Fisher's $r$ - $z$. test revealed that the relationship between disgust and moral judgment was significantly stronger among those who endorsed evaluative simulation, $z=3.23, p=.002$ (ES $r(162)=.55, p<.001, \mathrm{OA} r(222)=.30, p<.001)$.

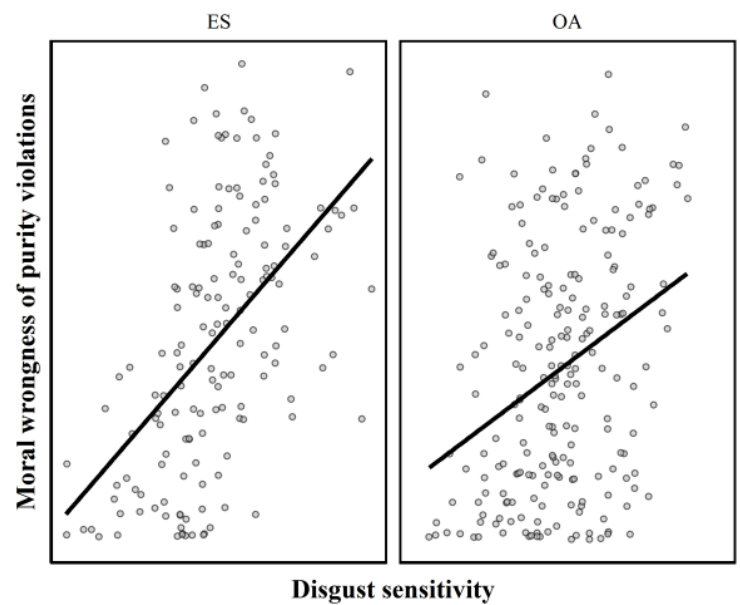

Figure 2. Moral wrongness of purity violations by disgust sensitivity (ES: evaluative simulation; OA: outcome assessment).

We confirmed this difference by entering disgust sensitivity, endorsement (1: evaluative simulation, 0: outcome assessment) and their interaction into a multiple regression model predicting moral judgment, $F(3,384)=31.4$, $p<$ $.001, r^{2}=.20$. This analysis revealed main effects of disgust sensitivity, $\beta=0.29, t=4.72, p<.001$, and evaluative simulation, $\beta=0.12, t=2.55, p=$ .011 , and, critically, the predicted interaction as well, $\beta=0.17, t=2.73, p=.007$ (see Figure 2), indicating that the effect of disgust sensitivity on moral judgment was moderated by one's approach to third-party moral judgment.

\subsection{Discussion}

Condemnation of purity violations was linked to a structural emphasis on actions, but not on outcomes. Our data indicated also that participants who employed evaluative simulation tended to condemn these behaviors more than did participants who performed an assessment of the action's outcomes. Finally, we found that disgust sensitivity better predicted moral judgment among participants who employed evaluative simulation.

We suggest that, when faced with the demand to make moral judgments about victimless crimes, many participants adopt the perspective of the third-party agent and simulate the performance of the target action. To the extent that they consider the action disgusting for themselves to perform, they also consider it morally wrong for others. Therefore, along with other recent reports (Lieberman \& Lobel, 2012, Miller et al., 2014), Study 2 provides convergent evidence for the role of evaluative simulation in third-party moral judgment. As such, it helps us to interpret evidence for variability among liberals and conservatives in their endorsement of evaluative simulation as one element of broader variability in the structural emphasis on actions versus outcomes. Finally, the results of Study 2 provide important validation for our novel measure of structural emphasis in the moral domain.

\section{Study 3}

One successful approach to characterizing the morality of liberals and conservatives, known as moral foundations theory, highlights differences in the content of their moral codes (Graham et al., 2009; Haidt \& Graham, 2007). According to this theory, diverse moral concerns can be meaningfully organized as a superordinate structure of five moral foundations. Of these five foundations, political liberals are concerned primarily with two: harm/care, and fairness. In contrast, political conservatives demonstrate more uniform concern for all five foundations, including loyalty toward the ingroup, respect for authority, and purity.

In Study 3, we examine the link between structural emphases on actions versus outcomes and these content-based moral foundations. With the harm and fairness foundations, we predicted a strong association to outcome focus. We also predicted a strong relationship with action focus, insofar as one might moralize harm motivated by an aversion to harmful action (throwing a punch) just as much as by the empathic concern that its outcomes trigger (causing a bruise; as observed in Cushman, Gray, Gaffey, \& Mendes, 2012; Miller et al., 2014). Consistent with the results of Study 2 , we predicted that concerns about purity relate exclusively to a structural emphasis on actions. Finally, we consider it an open question whether the remaining moral foundations, ingroup/loyalty, 
and authority, are supported by action or outcome focus. Some violations-for instance, insulting a family member, or cursing one's nation on the radio-cause others pain and distress. Critically however, they need not: Other actions, like burning one's national flag in private, do not result in harmful outcomes and yet nevertheless may be viewed as violations of loyalty and/or authority. This suggests that a structural emphasis on actions may play a special role in the moralization of loyalty and respect for authority, as it does with sanctity and purity.

\subsection{Methods}

563 participants (317 women) voluntarily logged on to the Moral Sense Test, read a brief introduction to the study and provided their written consent. Next, participants completed the assessment of structural emphasis, along with the Moral Foundations Questionnaire (MFQ; Graham et al., 2009).

In the first part of the MFQ, participants rated the relevance of various abstract moral criteria: e.g., 'Whether or not someone acted unfairly' (fairness) and 'Whether or not an action caused chaos or disorder' (authority). In the second part, participants reported their agreement with claims each reflecting a particular moral concern: e.g., 'One of the worst things a person could do is hurt a defenseless animal' (harm), 'It is more important to be a team player than to express oneself (ingroup/loyalty), and 'Chastity is an important and valuable virtue' (purity).

Applying the attentiveness filter recommended by MFQ developers (i.e., 4 or above on 'Whether or not someone was good at math', 3 or below on 'It is better to do good than to do bad' on a 1-6 scale) resulted in 92 participants being excluded from subsequent analyses. At the end of the experiment, participants optionally provided demographic information.

\subsection{Results}

The extent to which participants exhibited a structural emphasis on actions correlated with their concern for all five moral foundations, whereas the extent to which they emphasized outcomes correlated only with their concern for the individualizing foundations of harm and fairness (see Table 2 and Figure 3). Our measures of third-party evaluation revealed the corresponding pattern of relations: ratings of evaluative simulation correlated with moralization across all five foundations, whereas ratings of outcome assessment correlated only with moralization of the individualizing foundations (see Table 2).

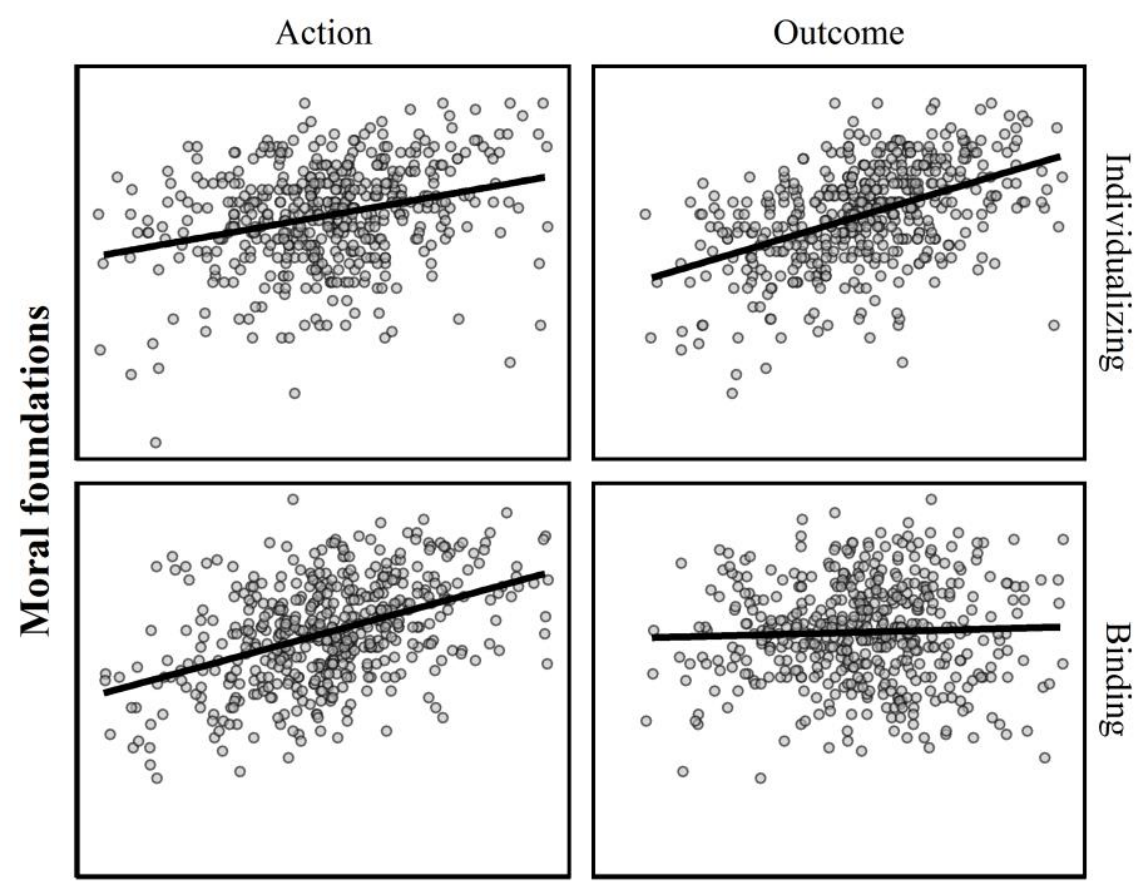

Structural emphasis

Figure 3. Relevance of individualizing and binding foundations by structural emphases. 
Table 2. Structural emphases and moral foundations $(n=471)$.

\begin{tabular}{l|lllll}
\multicolumn{1}{c}{ Harm } & Fairness & Loyalty & Authority & Purity \\
\hline \multirow{2}{*}{ Action focus } & .30 & .23 & .28 & .38 & .45 \\
& $(.000)$ & $(.000)$ & $(.000)$ & $(.000)$ & $(.000)$ \\
Outcome focus & .43 & .42 & .08 & .01 & .02 \\
Evaluative simulation & $(.000)$ & $(.000)$ & $(.07)$ & $(.91)$ & $(.71)$ \\
& .14 & .11 & .14 & .20 & .23 \\
Outcome assessment & $(.002)$ & $(.02)$ & $(.002)$ & $(.000)$ & $(.000)$ \\
& .32 & .33 & -.01 & -.05 & -.07 \\
& $(.000)$ & $(.000)$ & $(.76)$ & $.26)$ & $(.14)$ \\
\hline
\end{tabular}

We then entered our measures of structural emphasis along with social political orientation into separate multiple regressions predicting each of the moral foundations. Again we observed significant effects of action focus on all five foundations, $0.23<\beta s<0.37$, $p$ s $<.001$, and of outcome focus on the individualizing foundations, $0.38<\beta$ s $<0.43$, ps $<.001$, after controlling for the effects of political orientation. Similarly, we entered our measures of third-party evaluation along with social political orientation into separate multiple regressions predicting each of the moral foundations. Here, too, we observed independent effects of evaluative simulation, $0.16<\beta \mathrm{s}<0.18$, ps $<.001$, and outcome assessment, $0.27<\beta$ s $<$ $0.32, \quad p s<.001$, on the individualizing foundations, after controlling for political orientation. The effects of evaluative simulation on each of the binding foundations after controlling for political orientation were significant (loyalty $\beta=0.09, p=.03$, authority $\beta=$ $0.14, p=.001$, purity $\beta=0.16, p<.001$ ), though their overall sizes were small. In sum, the effects of participants' structural emphases on their pattern of moral foundations held even after controlling for political orientation.

\subsection{Discussion}

As predicted, participants' structural emphases were systematically related to the content of their moral values. Specifically, an emphasis on actions was associated with a five foundation morality (i.e., the conservative moral profile) whereas an emphasis on outcomes was associated with a harm-based, two foundation morality (i.e., the liberal moral profile). This illustrates that our present structural approach to differences in moral values across the political spectrum complements past content-based approaches. In particular, we may be able to understand the conservative concern with authority, loyalty and especially purity in part through the structural insight that violations in these domains are often more strongly associated with intrinsically bad actions than with the expectation of bad outcomes.

\section{Study 4}

Recent reports indicate that political conservatives are more likely to condemn the sacrifice of an innocent victim when it is motivated by the greater good (Graham et al., 2017; Piazza \& Sousa, 2014). This result is straightforwardly predicted by a structural approach, since the moral condemnation of these canonically harmful actions rests on an aversion to the action of causing up-close personal harm (Miller et al., 2014; Patil, 2015).

Critically, we also examined participants' concern for each of the five moral foundations. The most straightforward application of a content-based approach predicts that the condemnation of these harmful actions in trolleytype dilemmas is motivated by care for the victim and, therefore, that moral judgments about these dilemmas will correlate strongly with ratings of the harm/care foundation (but weakly with the remaining foundations, if at all). In contrast, the structural perspective predicts that individuals who oppose utilitarian sacrifice in high-conflict dilemmas also endorse the binding foundations, and particularly purity, since both depend upon a structural emphasis on actions, as seen in Studies to 2 and 3 . This would illustrate the way in which a structural approach to moral judgment can make unique predictions that are not fully captured when adopting a content-based approach alone.

\subsection{Methods}

143 participants (81 women) voluntarily logged on to the Moral Sense Test (MST), read a brief introduction to the study and provided their written consent. Next, they viewed three highconflict personal moral dilemmas in a random order (Trolley, Crying Baby, and Lifeboat adapted from Greene et al., 2001), and rated the moral wrongness of the agent's behavior from 1: 'Not morally wrong at all' to 7: 'Very morally wrong'. Participants also completed the MFQ. The order of presentation of the dilemmas block and the 
MFQ was counterbalanced across participants. As in Study 3, we applied the recommended attentiveness filter which resulted in 20 exclusions. At the end of the study, participants voluntarily provided demographic information.

\subsection{Results}

Judgments of the three moral dilemmas were averaged into a single index of moral judgment per participant $(a=.73)$. Moral judgments of trolley-type dilemmas correlated with political orientation on social issues, $r(123)=.28, p=.002$, and fiscal issues, $r(123)=.23, p=.01$, and marginally with familial political orientation, $r(123)$ $=.17, p=.06$, indicating that conservatives tended to condemn personal harm in utilitarian trade-offs more than did liberals (see Figure 4).

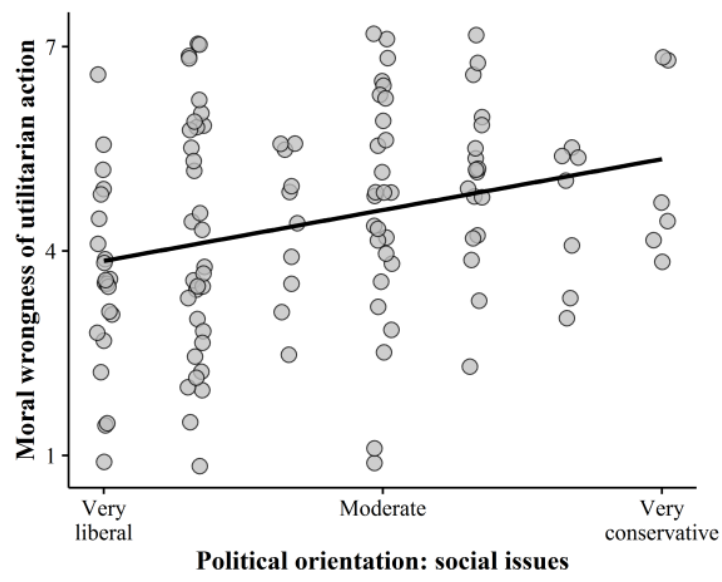

Figure 4. Moral wrongness of utilitarian action by political orientation on social issues.

Next, we turned to the relationship between judgments of the moral dilemmas and the moral foundations. As predicted by the content-based approach, condemnation of personal harm correlated with ratings of the harm foundation, $r(123)=.36, p<.001$. However, as predicted by the structural hypothesis alone, we found correlations between condemnation of personal harm and the binding foundations; loyalty $r(123)$ $=.29, p=.01$, authority $r(123)=.34, p<.001$, purity $r(123)=.43, p<.001$, indicating that deontological participants tended to care about loyalty, respect for authority, and most of all purity.

\subsection{Discussion}

The results of Study 4 provided support for both content-based and structural approaches. Consistent with a content-based approach, moralization of the harm foundation predicted deontological moral judgment. Meanwhile, consistent with a structural approach, endorsement of purity concerns also predicted deontological moral judgment of dilemmas. If anything, this latter correlation appeared to be the stronger of the two.

Of course these two approaches are not mutually-exclusive. Rather, they complement each other insofar as certain contents (i.e., foundations) are closely aligned with a structural emphasis on negative outcomes (particularly harm) and others are difficult to understand except in terms of a structural emphasis on aversive actions (most obviously purity).

\section{Study 5}

Our first four studies demonstrate the merits of characterizing the moral attitudes of liberals and conservatives in terms of underlying structural emphases. In Study 5, we take a further step by relating these differences to psychological traits that extend beyond the moral domain.

Various studies have shown that the condemnation of victimless crimes and utilitarian trade-offs relies on intuitive thought, with reflection favoring more permissive judgments (Bartels, 2008; Feltz \& Cokely, 2008; Moore, Clark, \& Kane, 2008; Paxton, Ungar \& Greene, 2012). These results open up the possibility that the moral profiles of conservatives and liberals are partly explained by differences in cognitive style (Jost, Kruglanski, \& Simon, 1999). But how might a preference for intuition lead to stricter sexual norms or stronger favoritism towards the ingroup, for instance, while a preference for reflection leads to a selective concern with harm and fairness? Through the lens of a content-based approach it is not obvious why this should be.

Adopting a structural approach, however, these connections are more readily explained. Imagine a teacher slapping a student in the face for wetting his pants. Through a structural emphasis on actions, a categorical aversion to slapping children may give rise to the simple judgment that the teacher's action is inherently wrong. The evaluation can be as simple as 'slapping children feels very certainly like a bad action'. A structural emphasis on outcomes invites a more demanding thought process, insofar as the teacher's action may have a multitude of potential outcomes. Beyond the child's immediate pain and humiliation, it may also discourage the child's undesirable behavior, decrease his self-esteem, deteriorate his relationship with the teacher, and may also indirectly affect others-for instance, it may influence the child to behave violently towards his peers. Moreover, there is uncertainty 
associated with each of these outcomes: they may or may not happen.

These connections, between action- versus outcome-based valuation and cognitive complexity are well-documented in the literature on reinforcement learning (Sutton \& Barto, 1999). In model-based approaches to reinforcement learning, a causal and probabilistic representation of the environment yields predictions about an action's value and guides instrumental choice. Yet actions may also acquire inherent value, using estimates of their outcomes based on past experience and habitization-a strategy which forms the basis of model-free learning. Recent experimental evidence shows that model-based learning recruits cognitive control and working memory (Otto et al., 2013a), and depends on related neural structures in the prefrontal cortex (Lee, Shimojo \& O'Doherty, 2014; Gläscher et al., 2010). Meanwhile, disrupting executive functioning through either a concurrent cognitive load (Otto, Raio, Chiang, Phelps \& Daw, 2013) or transcranial magnetic stimulation (Smittenaar, FitzGerald, Romei, Wright \& Dolan, 2013) increases the scope of model-free decisionmaking.

Together these considerations suggest that making moral judgments by assessing how an action 'feels' depends on model-free, intuitive processes (akin to the affect heuristic in Slovic, Finucane, Peters, \& MacGregor, 2002), while moral judgments based on the expected outcomes of an action require a more cognitively complex search over probabilistic causal models. We therefore predict that participants with an intuitive cognitive style will exhibit a structural emphasis on actions, while participants with a reflective cognitive style will exhibit a structural emphasis on outcomes. In addition, this relationship may underlie disagreements about the moral relevance of binding foundations: authority, loyalty, and purity violations. So, in Study 5 we also show how the structural perspective can help to bridge between moral foundations theory and the established differences in cognitive style across the political spectrum.

\subsection{Methods}

216 participants (128 women) were recruited via Amazon's Mechanical Turk (www.mturk.com), an online labor market where short incentivized tasks are completed by workers worldwide.

Participants provided their written consent and then completed two widely-used measures of cognitive style-the 18-item Need for Cognition Short Form (Cacioppo, Petty, \& Kao, 1984), and the 42-item Need for Closure Scale (Webster \& Kruglanski, 1994)—along with our measures of structural emphasis and the MFQ, in a randomized order to avoid the influence of systematic order effects upon our data. At the end, participants optionally provided basic demographic information.

Need for cognition measures the extent to which participants enjoy effortful thought and tend to engage in reflection. Need for closure measures the need to possess definitive knowledge, instead of enduring ambiguity or indecision. So individuals who are high in need for closure tend to seek definitive knowledge, which is associated with a preference for order and an intolerance of unpredictability. By contrast, people who are low in need for closure are more likely to endure uncertainty and ambiguity, and hold higher standards of evidence in forming beliefs.

\subsection{Results}

We replicated previous findings demonstrating a relationship between cognitive style and political orientation (Jost et al., 1999): specifically, high need for closure and low need for cognition were associated with social conservatism, closure $r(214)$ $=.22, p=.001$, cognition $r(214)=-.19, p=.006$, but bore no relationship to fiscal conservatism, $p$ s $>$.5. Need for cognition and need for closure were themselves negatively correlated, $r(216)=$ $.22, p=.001$.

As predicted, action focus correlated positively with need for closure, $r(216)=.31, p<.001$, and negatively with need for cognition, $r(216)=-.19, p$ $=.005$, confirming that action focus was associated with an intuitive cognitive style. By contrast, outcome focus did not correlate with either index, $p s>.2$ (see Figure 5). Controlling for political orientation, in separate multiple regression models the effects of action focus on indices of cognitive style remained significant, closure $\beta=0.30, p<.001$, cognition $\beta=-0.18$, $p$ $=.006$. In contrast, approaches to third-party evaluation were not related with measures of cognitive style, all $p$ s $>.1$.

Table 3. Cognitive style and moral foundations $(n=216)$.

\begin{tabular}{l|lllll}
\multicolumn{1}{c}{} & Harm & Fairness & Loyalty & Authority & Purity \\
\hline \multirow{2}{*}{ NCog } & -.03 & -.07 & -.31 & -.28 & -.31 \\
& $(.62)$ & $(.32)$ & $(.000)$ & $(.000)$ & $(.000)$ \\
NClos & .11 & .10 & .20 & .21 & .31 \\
& $(.12)$ & $(.16)$ & $(.003)$ & $(.001)$ & $(.000)$ \\
\hline
\end{tabular}




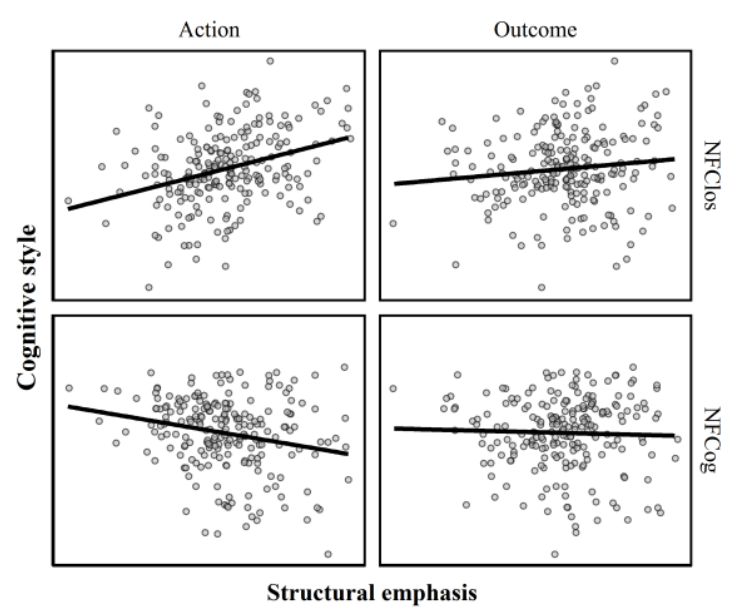

Figure 5. Need for closure (NFClos) and need for cognition (NFCog) by structural emphases.

\subsubsection{Mediation analysis}

We found that an intuitive cognitive style predicted moralization of the binding foundations (but not individualizing foundations, see Table 3), which might be expected given that both are associated with a structural emphasis on actions. Consequently, we performed a mediation analysis to determine whether a structural emphasis on actions mediates the observed relationship between thinking style and endorsement of binding foundation moral values. We aggregated the binding foundations into a single index ( $a=$ $.80)$ and entered it as our dependent measure. Action focus partially mediated the effects of need for closure (Sobel-Goodman $z=3.22, p=.001$, mediated/total effect $=.31$ ) and need for cognition (Sobel-Goodman $z=-2.60, p=.007$, mediated $/$ total effect $=.17$ ).

\subsection{Discussion}

As predicted, our results indicated that an intuitive cognitive style supports a structural emphasis on actions. In contrast, we found minimal relationships between cognitive style and our measures of evaluative simulation of thirdparty behavior. One explanation for this might be that whether we take our aversions to particular actions into account when deciding what is right for us to do is largely due to a general reliance on intuition. But, given those feelings, whether we employ them to judge others through evaluative simulation is not influenced by cognitive style (although it does relate to political orientation, as demonstrated in Study 1).

We found a relation between cognitive style and social political orientation, but no relation with fiscal political orientation (see Iyer, Koleva, Graham, Ditto, \& Haidt, 2012). Together with the results of Study 1 (where differences in structural emphases were larger with social than fiscal political orientation too), this suggests that the phenomenon of interest, i.e., how cognitive style gives rise to distinct approaches to morality among liberals and conservatives, primarily applies to the social dimension of political ideology.

Finally, we found that cognitive style was systematically related to our measures of action focus, but not outcome focus. We did not anticipate this result, which deserves further investigation. Possibly, our outcome items index the recognition that outcomes matter in the abstract, which is not cognitively demanding or ambiguous (see Ditto \& Liu, 2012). Rather, cognitive demands and ambiguity may arise principally in the process of making outcomebased moral judgments in practice.

At a broad level, the results of Study 5 suggest a potential link between two well-studied aspects of political psychology that have previously been treated independently: cognitive style (Amodio, Jost, Master, \& Yee, 2007; Jost et al., 1999) and moral foundations theory (Graham et al., 2009; Haidt \& Graham, 2007).

\section{General Discussion}

Moral disagreements along the political spectrum appear to derive not only from a concern for divergent moral domains, but also from different structural approaches to moral evaluation. Specifically, we find that liberals emphasize the value of outcomes (e.g., 'In order to be moral you have to pay close attention to the impact of your decisions'), while conservatives emphasize the value of actions (e.g., 'By and large, morality is about doing what feels right'). The preference for action-based moralization is associated with an approach to moral judgment we have termed 'evaluative simulation' (Hannikainen, 2014; Miller \& Cushman, 2013)i.e., if it feels aversive to me, it's morally wrong for you - and also helps to explain several characteristic features of conservative moral thinking.

First, a structural emphasis on actions predicts the tendency to condemn harmless taboo behaviors, like consensual sibling incest. Past research attributes the condemnation of these behaviors to a feeling of disgust (Haidt et al., 1993; Horberg et al., 2009; Inbar et al. 2009), and here we show that this relationship is linked with the process of evaluative simulation. Specifically, the association between disgust proneness and moral judgment is strongest among those who endorse evaluative simulation as an approach to judging others. 
Second, we show that the conservative and liberal approaches to moral judgment correspond with previously reported differences in the content of their moral codes (Graham et al., 2009). A focus on the intrinsic wrongness of action-types is associated with a concern for all moral foundations, especially loyalty to the ingroup, respect for authority, and purity, while a focus on outcomes is associated with valuing care and fairness only. These relationships held even when controlling for political orientation.

Third, we find convergent evidence that the condemnation of utilitarian trade-offs in trolleytype dilemmas is associated with action-based moral values (Miller et al., 2014; Patil, 2015). And, as predicted by the structural approach, we observe also that conservatives are more likely than liberals to oppose harming one to save many, consistent with other recent studies (Graham et al., 2017; Piazza \& Sousa, 2014).

Finally, we link the structural perspective to a growing body of evidence for the roles of intuition versus reflection in moral judgment. Specifically, we find that an action focus is associated with an intuitive thinking style, even after controlling for political orientation. As such, the present study helps to link two influential but previously independent lines of research concerning political orientation: trait differences in cognitive style, on the one hand, and moral foundations theory, on the other.

Our results can be construed in terms of a dual-process theory of moral judgment, positing an intuitive system responsible for the evaluative simulation of actions and a controlled system performing an assessment of its expected outcomes (Cushman, 2013; Greene, 2007; Hannikainen, 2014), such that moral attitudes derive from differences in the reliance on and interplay between these neurocognitive systems. This interpretation is consistent with evidence that neural structures commonly associated with intuitive-affective processing are recruited during the experience of disgust (left insula: Carr, Iacoboni, Dubeau, Mazziotta, \& Lenzi, 2003), and during the condemnation of personal harm (amygdala: Shenhav \& Greene, 2014; mPFC: Greene et al., 2001 2004; Koenigs et al., 2007) and purity violations (amygdala: Schaich-Borg, Lieberman \& Kiehl, 2008). Meanwhile, neural regions involved in effortful, cognitive processing (most notably the anterior cingulate cortex, and the dorsolateral prefrontal cortex) are implicated in the utilitarian resolution of high-conflict dilemmas (Greene et al., 2004; Shenhav \& Greene, 2010). Finally, separate studies report corresponding structural (amygdala, ACC: Kanai, Feilden, Firth, \& Rees, 2011) and functional (ACC: Amodio et al., 2007) differences in the brains of conservatives and liberals. Therefore, the model of action- and outcome-based valuation offers a theoretical framework to understand disagreements between liberals and conservatives in the moral domain in terms of underlying neurocognitive capacities and their contributions to moral evaluation.

Together these results might be considered to paint an unflattering portrait of the conservative moral sense. In place of a consideration of how people's actions harm or help those affected, conservative judgments about what is right and wrong for others depend to a larger extent on projecting personal, automatic aversions: if it feels bad to me, it's wrong for you. For example, it has been shown that people-left and right-exhibit an implicit attitude of disapproval towards male homosexuality (Inbar, Pizarro, Knobe, \& Bloom, 2009), which may be the result of evaluative simulation. When it comes to making explicit moral judgments about male homosexuality, social conservatives tend to employ this aversion as the basis for condemnation, while liberals suppress it in favor of an assessment based on considerations of welfare.

Second, action-based moral evaluations may also misdirect efforts to address certain collective action problems. In real-life contexts, we face a wide range of commonplace dilemmas-who to vote for in a presidential election, or whether to use disposable plastics, buy sweatshopmanufactured clothing, or take a long flight, to name a few-that involve significant and welldocumented aggregate effects, non-locally and in the long run. These behaviors do not immediately lead to proximate cues of harm, and their negative consequences are not easily traced back to token actions-two features that prevent processes of model-free reinforcement learning from moralizing these behaviors intrinsically. Therefore, in contexts like these, model-based reasoning alone may be able to produce meaningful estimates of the moral value of behavior, legislation and policy.

The above examples illustrate ways in which action- and outcome-based approaches yield divergent value judgments, in line with the characteristically conservative (e.g., moralizing homosexuality but not global warming) and liberal (i.e., moralizing global warming but not homosexuality) views. Together with recent work elucidating the origin and mechanism of actionbased moral values (Cushman et al., 2012; 
Lieberman \& Lobel, 2012; Miller et al., 2014), our present study may aggravate concerns, championed by utilitarian theorists (Greene, 2007; Singer, 2005), that our intuitive moral sense is not conducive to the resolution of contemporary moral challenges.

At the same time, an action focus bestows various computational and social benefits in ordinary contexts (Bennis, Medin, \& Bartels, 2010). In the real world, model-based reasoning is rife with uncertainty and complexity at each step: identifying the expected outcomes of each potential action, assigning magnitude and probability to each anticipated outcome, comparing qualitatively distinct outcomes, and so on. By contrast, there is a cognitive efficiency inherent to heuristic approaches, whether these depend on the application of explicit rules (Gigerenzer \& Brighton, 2009) or implicit approximations (Otto et al., 2013a). In addition, recent research shows that explicit reasoning does not always enhance accuracy (Kool, Cushman \& Gershman, 2016) and in fact in some cases may interfere (Gaissmaier \& Schooler, 2008). These problems are further aggravated by evidence that outcome-based assessments are not insulated from processes of motivated reasoning (Ditto \& Liu, 2012). So debates about utility maximization may to some degree constitute attempts to align facts with personal goals and values.

Furthermore, processes of evaluative simulation might be expected to foster the development of morally and ideologically defined communities, a consequence that is compatible with the theory of conservative ideology as binding moral groups (Haidt \& Graham, 2009). This may occur because relying on simple rules enables the adoption of bright-line standards of conduct, including cooperation (Rand, Greene \& Nowak, 2012) and honesty (Greene \& Paxton, 2009), which motivate interpersonal trust (Everett, Pizarro \& Crockett, 2016) and positive character ascriptions (Critcher, Inbar, \& Pizarro, 2013). Along similar lines, evaluating others' actions by comparing them against the standard of one's own conscience would, at least in theory, reduce moral hypocrisy.

Although these consequences may strengthen ties within moral groups, they may also provide the basis for hostility between them: Greene (2014) argues that moral systems structured around categorical, act-based prohibitions are especially susceptible to between-group conflict, whereas those structured around more flexible principles of welfare maximization are less so.

Our analysis echoes two familiar themes of the social sciences: Conservative values give rise to stable, cooperative and tight-knit communities, while liberal values are particularly well-suited to accommodate diversity and flexibly respond to change. The present study offers some insight into why, via underlying structural emphases. Oftentimes, an emphasis on outcomes is needlessly complex, and even misguided, while categorical rules governing action-types provide advantageous strategies for behavior regulation and group cohesion. In other (particularly novel) contexts, model-free assessments of value derive moral rules that are acutely insensitive to their consequences, and only counter-intuitive moral reasoning may be capable of advancing broader welfare interests. This predicament invites applied ethicists to undertake the prescriptive challenge of furnishing precise guidelines about when to advocate act-based intuition versus impact-based reasoning across moral, legal and political decision contexts.

Finally, we must note several limitations of the studies presented here. First, our inferences depend upon correlation. Future work should therefore aim to test the proposed claims in the context of an experimental design (Hannikainen \& Cushman, unpublished data). Second, given the liberal bias in our sample, it is important to note that characterizations of liberals and conservatives are better thought of as claims about how liberals differ from both moderates and conservatives. Third, there are public policy issues on which the structural approach makes the wrong prediction. For instance, a paradigmatic emphasis on outcomes would perhaps yield the view that the death penalty is morally preferable to life imprisonment in certain circumstances, or that intrusions on privacy for the greater good of society (as in wire-tapping) are morally permissible. Yet the typically liberal position on these matters is in fact the opposite. Finally, we must note that the effect sizes reported for moral foundations tend to be larger than the effect sizes we report here based on structural emphases. Of course, as we have indicated throughout, these approaches are not at all exclusive of each other, and indeed they appear to be mutually-reinforcing.

Still, this study offers a promising advance in our understanding of the psychological basis of moral attitudes along the political spectrum. Conservatives' and liberals' seemingly irreconcilable views about matters of right and wrong are partly the product of individual differences in the tendency to approach the evaluation of moral issues with an emphasis on simulating the agent's action versus on assessing 
its expected outcomes. This difference in their approaches to moral judgment dovetails with other well-known correlates of political orientation, and helps to explain disagreements on heated public policy debates, hypothetical dilemmas, and abstract moral standards.

\section{References}

Amodio, D. M., Jost, J. T., Master, S. L., \& Yee, C. M. (2007). Neurocognitive correlates of liberalism and conservatism. Nature Neuroscience, 10(10), 1246-1247.

Baron, J., \& Spranca, M. (1997). Protected values. Organizational Behavior and Human Decision Processes, 70(1), 1-16.

Bartels, D. M. (2008). Principled moral sentiment and the flexibility of moral judgment and decision making. Cognition, 108, 381-417.

Bennis, W., Medin, D., \& Bartels, D. (2010). The costs and benefits of calculation and moral rules. Perspectives on Psychological Science, 5(2), 187-202.

Cacioppo, J. T., Petty, R. E., \& Kao, C. F. (1984). The efficient assessment of need for cognition. Journal of Personality Assessment, 48(3), 306-307.

Carr, L., Iacoboni, M., Dubeau, M., Mazziotta, J., \& Lenzi, G. (2003). Neural mechanisms of empathy in humans: A relay from neural systems for imitation to limbic areas. Proceedings of the National Academy of Sciences, 100(9), 5497-5502.

Critcher, C. R., Inbar, Y., \& Pizarro, D. A. (2013). How quick decisions illuminate moral character. Social Psychological and Personality Science,4(3), 308-315.

Crockett, M. J. (2013). Models of morality. Trends in Cognitive Sciences, 17(8):363-6.

Cushman, F. A. (2013). Action, outcome and value: A dual-system framework for morality and more. Personality and Social Psychology Review, 17(3), 273-292.

Cushman, F. A., Gray, K., Gaffey, A., \& Mendes, W. (2012). Simulating murder: The aversion to harmful action. Emotion, 12(1), 2-7.

Cushman, F. A., Knobe, J., \& Sinnott-Armstrong, W. (2008). Moral appraisals impact doing/allowing judgments. Cognition, 108(1), 281-289.

Cushman, F. A., Young, L., \& Hauser, M. D. (2006). The role of conscious reasoning and intuition in moral judgment: Testing three principles of harm. Psychological Science, 7(12), 1082-1089.

Daw, N., \& Shohamy, D. (2008). The cognitive neuroscience of motivation and learning. Social Cognition, 26(5), 593-620.

Ditto, P. H., \& Liu, B. (2012). Deontological dissonance and the consequentialist crutch. In M. Mikulincer, P. R. Shaver (Eds.), The social psychology of morality: Exploring the causes of good and evil (pp. 51-70). Washington: APA Press.

Dayan, P., \& Niv, Y. (2008). Reinforcement learning and the brain: The good, the bad and the ugly. Current Opinion in Neurobiology, 18(2), 185-196.

Everett, J. A., Pizarro, D. A., \& Crockett, M. J. (2016). Inference of trustworthiness from intuitive moral judgments. Journal of Experimental Psychology: General, 145(6), 772.
Feltz, A., \& Cokely, E. T. (2008). The fragmented folk: More evidence of stable individual differences in moral judgments and folk intuitions. In B. C. Love, K. McRae, \& V. M. Sloutsky (Eds.), Proceedings of the 30th Annual Conference of the Cognitive Science Society (pp. 1771-1776). Austin, TX: Cognitive Science Society.

Gaissmaier, W., \& Schooler, L. J. (2008). The smart potential behind probability matching. Cognition, 109(3), 416-422.

Gershman, S. J., Markman, A. B., \& Otto, A. R. (2014). Retrospective revaluation in sequential decision making: A tale of two systems. Journal of Experimental Psychology: General, 143(1), 182-194.

Gigerenzer, G., \& Brighton, H. (2009). Homo heuristicus: Why biased minds make better inferences. Topics in Cognitive Science, 1(1), 107-143.

Gläscher, J., Daw, N. D., Dayan, P., \& O'Doherty, J. P. (2010). States versus rewards: Dissociable neural prediction error signals underlying model-based and model-free reinforcement learning. Neuron, 66(4), 585-595.

Graham, J., Haidt, J., \& Nosek, B. (2009). Liberals and conservatives use different sets of moral foundations. Journal of Personality and Social Psychology, 96, 1029-1046.

Graham, J., Iyer, R., Sherman, G. D., Hawkins, C. B., \& Nosek, B. (2017). Political ideology moderates nonpolitical moral decision-making processes. Manuscript submitted for publication.

Greene, J. D. (2007). The secret joke of Kant's soul. In W. Sinnott-Armstrong (Ed.), Moral Psychology, Vol. 3: The Neuroscience of Morality: Emotion, Disease, and Development. Cambridge, MA: MIT Press.

Greene, J. (2014). Moral tribes: Emotion, reason and the gap between us and them. Atlantic Books Ltd.

Greene, J. D., Nystrom, L. E., Engell, A. D., Darley, J. M., Cohen, J. D. (2004). The neural bases of cognitive conflict and control in moral judgment. Neuron, 44, 389-400.

Greene, J. D., Sommerville, R. B., Nystrom, L. E., Darley, J. M., \& Cohen, J. D. (2001). An fMRI investigation of emotional engagement in moral judgment. Science, 293, 2105-2108.

Haidt, J., \& Graham, J. (2007). When morality opposes justice: Conservatives have moral intuitions that liberals may not recognize, Social Justice Research, 20, 98-116.

Haidt, J., \& Graham, J. (2009). Planet of the Durkheimians, where community, authority, and sacredness are foundations of morality. In J. Jost, A. C. Kay \& H. Thorisdottir (Eds.), Social and psychological bases of ideology and system justification (pp. 371-401). New York: Oxford.

Haidt, J., Koller, S.H., \& Dias, M.G. (1993). Affect, culture, and morality, or is it wrong to eat your dog? Journal of Personality and Social Psychology, 65(4), 613-28.

Haidt, J., McCauley, C., \& Rozin, P. (1994). Individual differences in sensitivity to disgust: A scale sampling seven domains of disgust elicitors. Personality and Individual Differences, 16, 701-713.

Hannikainen, I. (2014). Evaluative focus: $A$ dual-process view of moral judgment(Doctoral dissertation). 
University of Sheffield, UK.

Hannikainen, I., Cabral, G., Machery, E., \& Struchiner, N. (2016). A deterministic worldview promotes approval of state paternalism. Journal of Experimental Social Psychology.

Horberg, E. J., Oveis, C., Keltner, D., \& Cohen, A. B. (2009). Disgust and the moralization of purity. Journal of Personality and Social Psychology, 97(6), 963-76.

Inbar, Y., Pizarro, D. A., \& Bloom, P. (2009). Conservatives are more easily disgusted than liberals. Cognition and Emotion, 23, 714-725.

Inbar, Y., Pizarro, D. A., Knobe, J., \& Bloom, P. (2009). Disgust sensitivity predicts intuitive disapproval of gays. Emotion, 9(3), 435-439.

Iyer, R., Koleva, S., Graham, J., Ditto, P., \& Haidt, J. (2012). Understanding libertarian morality: The psychological dispositions of self-identified libertarians. PloS ONE, 7(8), e42366.

Jost, J. T., Kruglanski, A. W., \& Simon, L. (1999). Effects of epistemic motivation on conservatism, intolerance, and other system justifying attitudes. In L. Thompson, D. M. Messick, \& J. M. Levine (Eds.), Shared cognition in organizations: The management of knowledge (pp. 91-116).

Kanai, R., Feilden, T., Firth, C., \& Rees, G. (2011). Political orientations are correlated with brain structure in young adults. Current Biology, 21(8), 677680.

Koenigs, M., Young, L., Adolphs, R., Tranel, D., Cushman, F. A., Hauser, M. D., \& Damasio, A. (2007). Damage to ventromedial prefrontal cortex increases utilitarian moral judgments. Nature, 446, 908-911.

Kool, W., Cushman, F. A., \& Gershman, S. J. (2016). When Does Model-Based Control Pay Off? PLoS Comput Biol, 12(8), e1005090.

Lee, S.W., Shimojo, S., \& O'Doherty, J.P. (2014). Neural computations underlying arbitration between model-based and model-free learning. Neuron 81(3): 687-699.

Lieberman, D., \& Lobel, T. (2012). Kinship on the Kibbutz: coresidence duration predicts altruism, personal sexual aversions and moral attitudes among communally reared peers. Evolution and Human Behavior, 33, 26-34.

Miller, R., \& Cushman, F. (2013). Aversive for me, wrong for you: First-person behavioral aversions underlie the moral condemnation of harm. Social and Personality Psychology Compass, 7(10), 707-718.

Miller, R., Hannikainen, I., \& Cushman, F. (2014). Bad actions or bad outcomes? Differentiating affective contributions to the moral condemnation of harm. Emotion, 14(3), 573-587.

Moore, A. B., Clark, B. A., \& Kane, M. J. (2008). Who shalt not kill? Individual differences in working memory capacity, executive control, and moral judgment. Psychological Science, 19, 549-557.

Olatunji, B. O., Williams, N. L., Tolin, D. F., Sawchuk, C. N., Abramowitz, J. S., Lohr, J. M., \& Elwood, L. (2007). The disgust scale: Item analysis, factor structure, and suggestions for refinement. Psychological Assessment, 19, 281-297.
Olson, L. R., \& Green, J. C. (2006). The religion gap. Political Science \& Politics, 39(3), 455-459.

Otto, A. R., Gershman, S. J., Markman, A. B., \& Daw, N. D. (2013a). The curse of planning: Dissecting multiple reinforcement-learning systems by taxing the central executive. Psychological Science, 24(5):751-761.

Otto, A.R., Raio, C.M., Chiang, A., Phelps, E., \& Daw, N. (2013b). Working-memory capacity protects model-based learning from stress. Proceedings of the National Academy of Sciences USA, 110: 20941-20946.

Patil, I. (2015). Trait psychopathy and utilitarian moral judgement: The mediating role of action aversion. Journal of Cognitive Psychology, 27(3), 349-366.

Paxton, J. M., Ungar, L., \& Greene, J. D. (2012). Reflection and reasoning in moral judgment. Cognitive Science, 36(1), 163-177.

Petrinovich, L., O’Neill, P., \& Jorgensen, M. (1993). An empirical study of moral intuitions: Toward an evolutionary ethics. Journal of Personality and Social Psychology, 64(3), 467-478.

Piazza, J. (2012). If you love me keep my commandments: Religiosity increases preference for rule-based moral arguments. International Journal for the Psychology of Religion, 22(4), 285-302.

Piazza, J., \& Sousa, P. (2014). Religiosity, political orientation, and consequentialist moral thinking. Social Psychological and Personality Science, 5(34), 334-342.

Rozin, P., Haidt, J., McCauley, C., Dunlop, L., \& Ashmore, M . (1999). Individual differences in disgust sensitivity: Comparisons and evaluations of paper-and-pencil versus behavioral measures. Journal of Research in Personality, 33, 330-351.

Schaich-Borg, J., Lieberman, D., \& Kiehl, K. (2008). Infection, incest, and iniquity: Investigating the neural correlates of disgust and morality. Journal of Cognitive Neuroscience, 20, 1529-1546.

Shenhav, A., \& Greene, J. D. (2010). Moral judgments recruit domain-general valuation mechanisms to integrate representations of probability and magnitude. Neuron, 67(4), 667-677.

Shenhav, A., \& Greene, J. D. (2014). Integrative moral judgment: dissociating the roles of the amygdala and ventromedial prefrontal cortex.The Journal of Neuroscience, 34(13), 4741-4749.

Singer, P. (2005). Ethics and intuitions. The Journal of Ethics, 9(3-4), 331-352.

Slovic, P., Finucane, M., Peters, E., \& MacGregor, D.G. (2002).The affect heuristic. In T. Gilovich, D. Griffin, \& D. Kahneman, (Eds.), Intuitive Judgment: Heuristics and Biases. Cambridge University Press.

Smittenaar, P., FitzGerald, T.H.B., Romei, V., Wright, N.D., \& Dolan, R.J. (2013). Disruption of dorsolateral prefrontal cortex decreases modelbased in favor of model-free control in humans. Neuron 80(4): 914-919.

Sutton, R. S., \& Barto, A. G. (1999). Reinforcement learning. MIT Press.

Webster, D. M., \& Kruglanski, A. W. (1994). Individual differences in need for cognitive closure. Journal of Personality and Social Psychology, 67, 1049-1062. 